\title{
Oncocytic Adrenocortical Carcinoma: A Morphologic, Immunohistochemical and Ultrastructural Study of Four Cases
}

\author{
Mai P. Hoang, M.D., Alberto G. Ayala, M.D., Jorge Albores-Saavedra, M.D. \\ Department of Pathology (MPH, JA-S), University of Texas Southwestern Medical Center, Dallas, Texas; \\ and M.D. Anderson Cancer Center (AGA), Houston, Texas
}

We present the clinical, histologic, immunohistochemical, and ultrastructural findings of four cases of non-functioning oncocytic adrenocortical carcinomas. The patients' ages ranged from 39 to 71 years. There was no sex predilection. Large yellowtan tumors $(8.5$ to $17.0 \mathrm{~cm})$, well demarcated from the adjacent kidney, were seen with a thin rim of normal adrenal gland along one edge. One tumor invaded the inferior vena cava and extended up to the level of the right atrium, and another metastasized to bone. The other two tumors had similar morphologic features and therefore were considered carcinomas. Histologic sections of all four cases showed a diffuse proliferation of polygonal neoplastic cells with large nuclei containing prominent nucleoli and abundant granular and eosinophilic cytoplasm. Occasional mononuclear and binucleated giant cells were noted in one case. There were rare mitotic figures (less than one per 10 high power fields). All tumors were immunoreactive for cytokeratins (AE1/AE3 and CAM5.2). Inhibin was focally expressed by one tumor and its bone metastasis. Ultrastructurally, the cytoplasm of the neoplastic cells was packed with innumerable mitochondria. Cytologic atypia or mitotic rate cannot reliably predict the biologic behavior of oncocytic adrenocortical neoplasms. Large tumor size (4/4), extracapsular extension (3/4), blood vessel invasion (2/4), necrosis (4/4), and metastasis (1/4) are features of malignancy for oncocytic adrenocortical carcinomas. The treatment of these tumors is complete surgical excision.

Copyright (C) 2002 by The United States and Canadian Academy of Pathology, Inc.

VOL. 15, NO. 9, P. 973, 2002 Printed in the U.S.A.

Date of acceptance: May 25, 2002.

Address reprint requests to: Jorge Albores-Saavedra, M.D., Department of Pathology, UT Southwestern Medical Center, 5323 Harry Hines Blvd, Dallas,

Texas 75390; e-mail: Jorge.albores@UTSouthwestern.edu; fax: 214-590-1411.
KEY WORDS: Adrenal cortical neoplasm, Adrenocortical carcinoma, Oncocytic neoplasm.

Mod Pathol 2002;15(9):973-978

Oncocytic adrenocortical neoplasms are rare, usually non-functioning tumors, found predominantly in adults. The majority of those reported have followed a benign clinical course (1-14). To date, three oncocytic adrenocortical carcinomas have been described; however, these cases emphasized only either the clinical presentation, the fine needle aspiration findings, or the ultrastructural features $(2,7,8)$.

We present the clinical, histologic, immunohistochemical, and ultrastructural features of four cases of oncocytic adrenocortical carcinoma. The cytopathologic findings of one case have been previously reported (7).

\section{MATERIALS AND METHODS}

The consultation file of two of the authors (JA-S, AGA) and the surgical pathology files of the University of Texas Southwestern Medical Center, Dallas, and M.D. Anderson Cancer Center, Houston, Texas, were searched for oncocytic adrenocortical carcinomas. Four cases with available archival materials were identified. The cytopathologic findings of one case (case 1) have previously been published (7). Four-micrometer thick sections were cut from the formalin-fixed, paraffin-embedded blocks and stained with hematoxylin and eosin. Additional paraffin sections of selected blocks were obtained for immunohistochemical studies, which were performed on an automated immunostainer (Ventana, Biotek System, Tucson, AZ) using the standard avidin-biotin peroxidase complex technique and the heat-induced epitope retrieval buffer. The primary antibodies are listed in Table 1. For electron microscopic study, tissue of three cases was fixed in $3 \%$ glutaraldehyde, postfixed in $1 \%$ osmium tetroxide, and thin sections were stained with lead citrate 
TABLE 1. Immunohistochemical Results of Four Cases of Oncocytic Adrenocortical Carcinomas

\begin{tabular}{|c|c|c|c|c|c|c|c|c|}
\hline Antibody & Case 1 & Case 2 & $\begin{array}{c}\text { Bone } \\
\text { Metastasis }\end{array}$ & Case 3 & Case 4 & Clone & Dilution & Source \\
\hline $\begin{array}{l}\text { High molecular weight } \\
\text { cytokeratin }\end{array}$ & + & + & + & + & - & $\mathrm{AE} 1 / \mathrm{AE} 3$ & $1: 800$ & Signet (Dedham, MA) \\
\hline $\begin{array}{l}\text { Low molecular weight } \\
\text { cytokeratin }\end{array}$ & ND & + & ND & + & + & CAM 5.2 & $1: 4$ & Becton Dickinson (Mountain View, CA) \\
\hline Vimentin & + & ND & + & + & + & polyclonal & $1: 200$ & DAKO (Carpinteria, CA) \\
\hline Synaptophysin & - & ND & + & ND & - & polyclonal & $1: 100$ & DAKO \\
\hline Chromogranin & - & ND & ND & ND & - & DAK-A3 & $1: 700$ & DAKO \\
\hline S-100 protein & - & ND & ND & ND & - & polyclonal & $1: 1200$ & DAKO \\
\hline Inhibin & - & + & + & - & - & polyclonal & $1: 20$ & Harlan Bioproducts (Indianapolis, IN) \\
\hline P53 & $10 \%$ & ND & ND & ND & - & DO7 & $1: 50$ & DAKO \\
\hline Ki-67 & $10 \%$ & ND & ND & $5 \%$ & $<5 \%$ & MIB-1 & $1: 40$ & Immunotech (Westbrook, ME) \\
\hline
\end{tabular}

ND, not done.

and uranyl acetate. All grids were examined with a JEOL 100SX electron microscope (Japan).

\section{RESULTS}

\section{Clinical Findings}

Case 1

A 39-year-old man presented with ascites, bilateral lower extremity edema, and abdominal mass. An abdominal computed tomography (CT) and arteriography revealed a large mass in the vicinity of the upper pole of the left kidney that invaded the inferior vena cava and extended up to the level of the right atrium. A thorough workup demonstrated no evidence of metastatic disease. He underwent a left radical nephrectomy and a combined cardiopulmonary bypass with atriotomy and resection of the tumor thrombus from the right atrium and inferior vena cava. The patient is free of disease 2 years and 8 months status postsurgery.

\section{Case 2}

A 53-year-old woman presented with a 7-month history of abdominal pain. A magnetic resonance imaging (MRI) scan showed a large retroperitoneal mass in the vicinity of the superior pole of the left kidney. A chest CT showed two $0.5 \mathrm{~cm}$ pulmonary nodules interpreted as metastases. A left adrenalectomy, nephrectomy, distal pancreatectomy, and splenectomy were performed. The patient developed a right proximal tibial metastasis a year later. She is alive with bone and pulmonary metastases 2 years after diagnosis.

\section{Case 3}

A 58-year-old man with known right adrenal mass presented with a 1-year-history of marked size increase. MRI showed a large and heterogeneous mass on $\mathrm{T} 1$ and $\mathrm{T} 2$ weighted images. The tumor displaced the kidney posteroinferiorly, effaced the right lobe of the liver, and caused moderate flattening of the inferior vena cava. A right adrenalectomy was performed. The patient is well and with no evidence of disease 2 years status postsurgery.

\section{Case 4}

A 71-year-old woman presented with a left abdominal mass. The left kidney, left adrenal gland, and spleen were resected. At the superior pole of the left kidney, a round, well-demarcated friable mass was seen with no direct attachment to the kidney. A CT scan of the chest and abdomen performed at 5 months status postsurgery demonstrated no evidence of residual or recurrent neoplasm.

\section{Gross Findings}

Large tumors, well-demarcated from adjacent kidney, were seen in all four cases. Focally, there was a thin rim of normally appearing adrenal gland along one edge. The tumors measured 8.5, 13.0, 14.0 , and $17.0 \mathrm{~cm}$ in greatest dimension, and showed a yellow-tan appearance with central stellate zone of necrosis (Fig. 1). The tumors invaded through the capsule into adjacent fibroadipose tissue in two cases (cases 1 and 2) and focally into the capsule in 1 case (case 3 ). Extension into the adrenal vein and renal vein was noted in case 1 .

\section{Microscopic Findings}

The adrenal glands of all four cases were almost completely replaced by a partially encapsulated neoplasm. Only a thin rim of residual normal adrenal gland remained. The polygonal neoplastic oncocytic cells were seen arranged predominantly in a diffuse pattern (Fig. 2). In some areas, nests and trabeculae of neoplastic cells separated by sinusoids lined by flattened endothelial cells were identified (Fig. 3). Large irregular zones of necrosis were noted. The neoplastic cells were large, round to polygonal, with round nuclei and prominent nucleoli, and abundant granular and eosinophilic cytoplasm (Fig. 4). Giant mononuclear and binucleated cells were seen in one case (case 4). Focal bizarre 


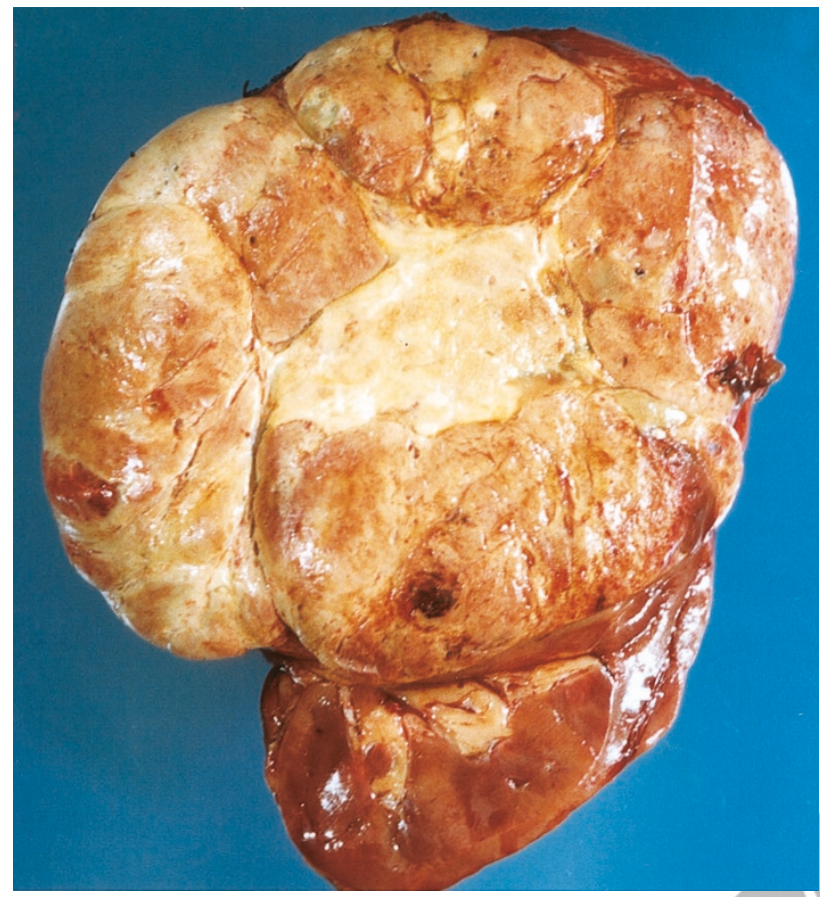

FIGURE 1. A large multinodular yellow tumor with central necrosis is seen replacing the adrenal gland and compressing the kidney.

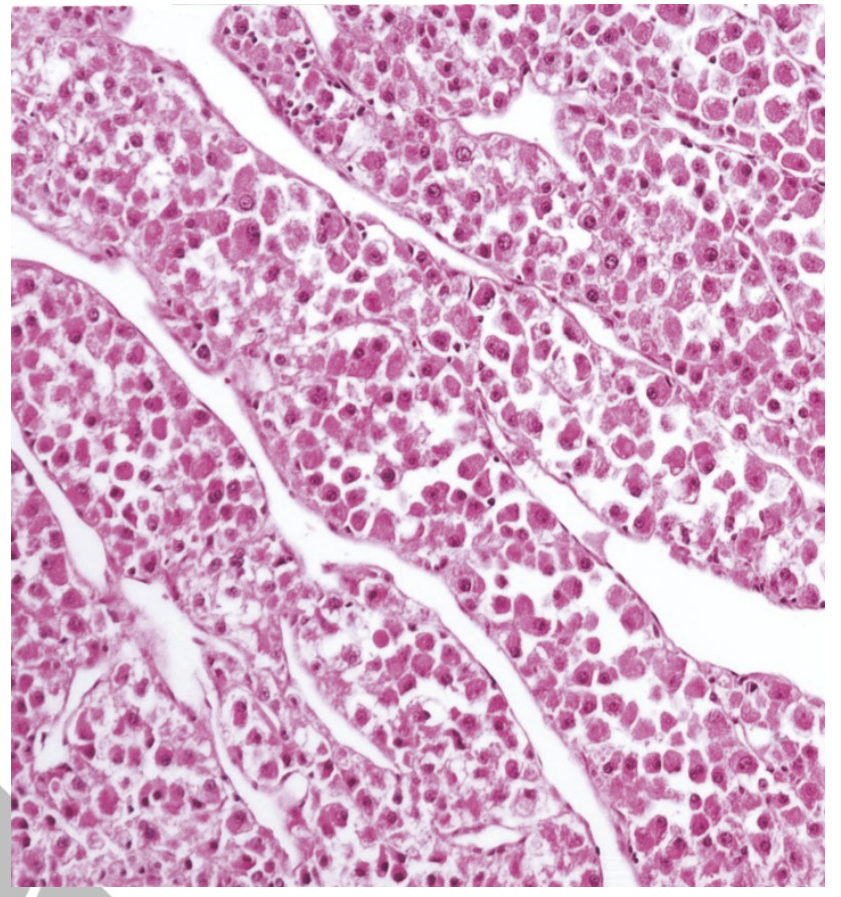

FIGURE 3. Trabeculae of tumor cells are separated by dilated sinusoids lined by endothelial cells.

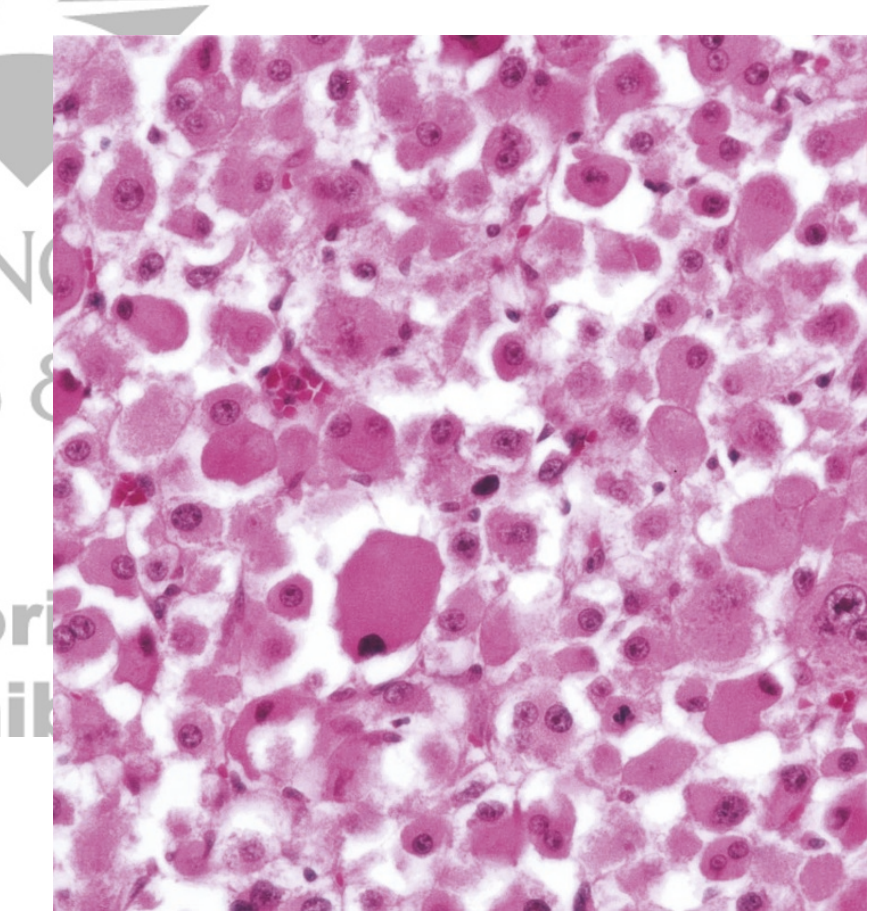

FIGURE 4. The neoplastic cells have abundant granular and eosinophilic cytoplasm. A binucleated cell with prominent nucleoli is seen.

proliferation of oncocytic neoplastic cells whose morphology was similar to that of the primary adrenal tumors.

The immunohistochemical results of four oncocytic adrenocortical carcinomas and the bone metastasis are summarized in Table 1 . All tumors were immunoreactive for cytokeratins (AE1/AE3 and CAM5.2) (Fig. 6). Inhibin was focally yet strongly positive in one tumor and its bone metastasis (Fig. 


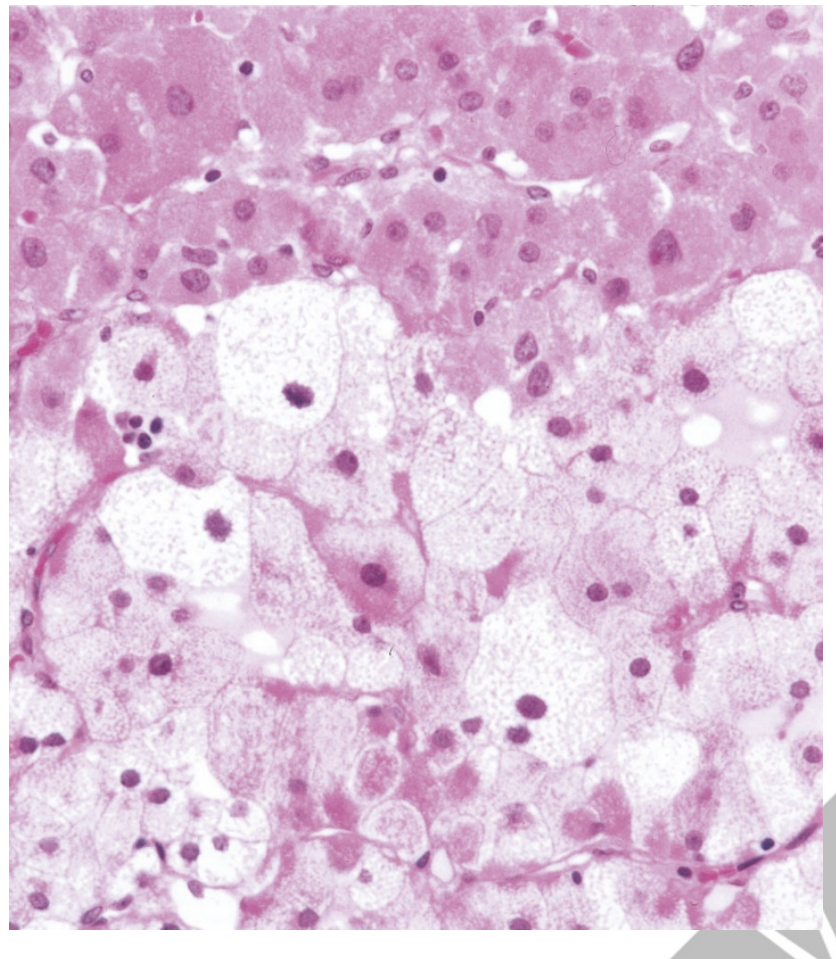

FIGURE 5. Aggregate of tumor cells with foamy cytoplasm is noted.

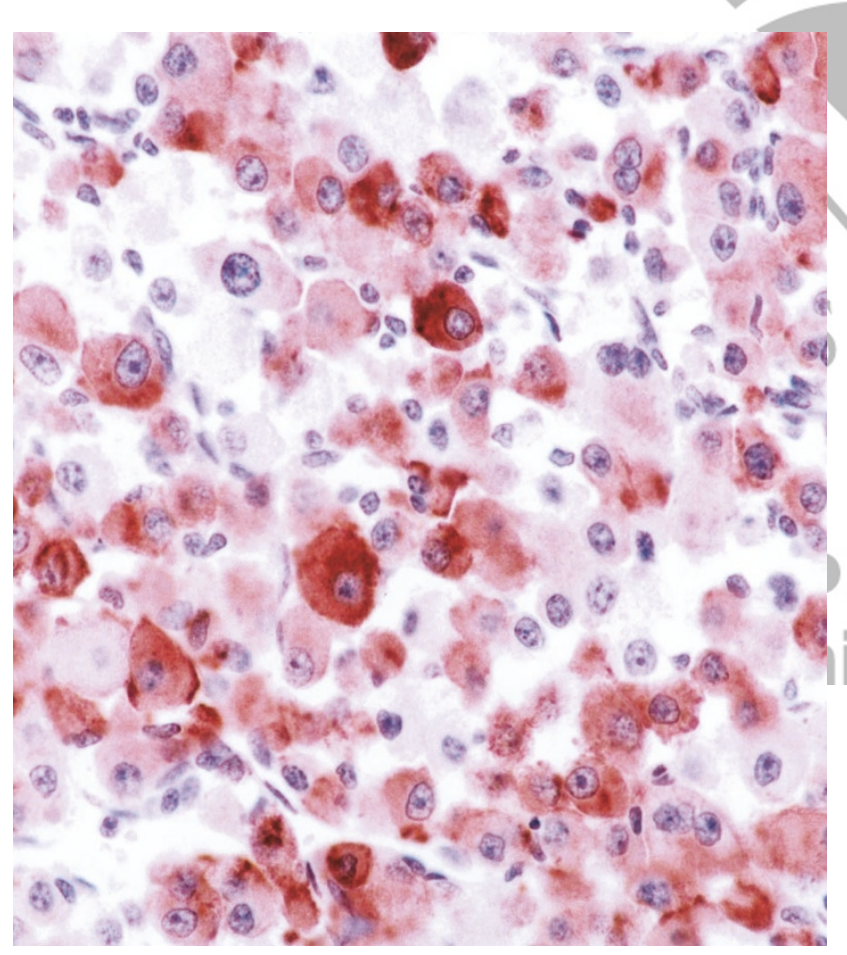

FIGURE 6. Strong cytokeratin (AE1/AE3) immunoreactivity.

7). The tumors were negative for synaptophysin, chromogranin and S-100 protein.

\section{Ultrastructural Findings}

The cytoplasm of the neoplastic cells of three tumors was packed with innumerable mitochon-

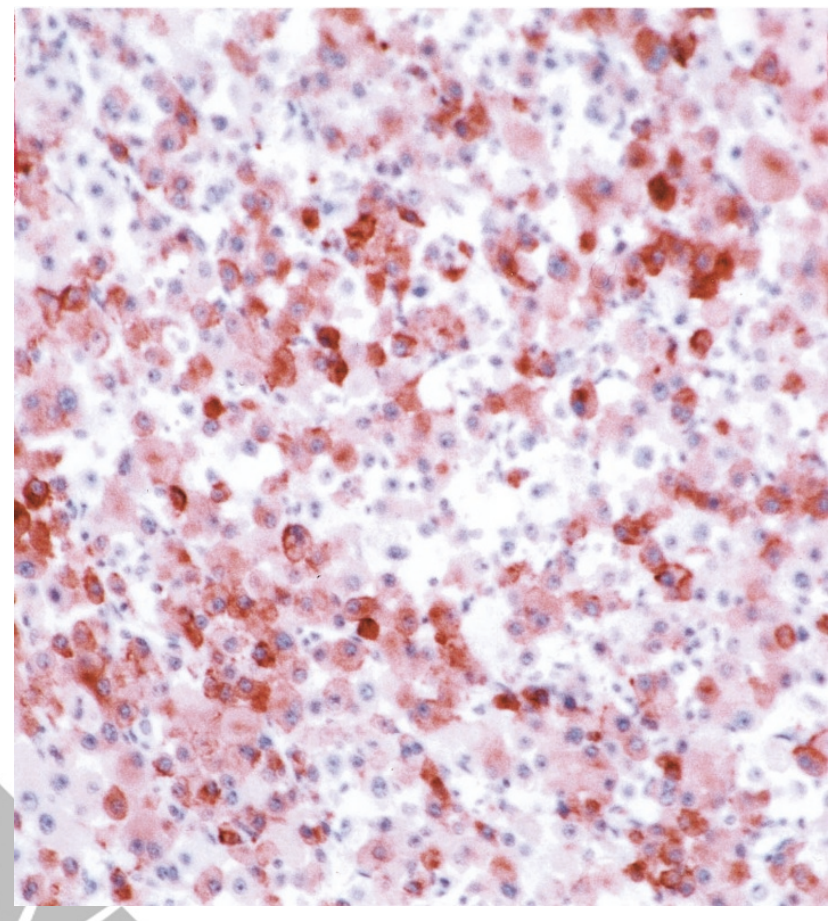

FIGURE 7. Strong inhibin immunoreactivity.

dria (Fig. 8). Lipid droplets and well-developed rough endoplasmic reticulum were identified. The abundant smooth endoplasmic reticulum and tubular cristae commonly seen in conventional adrenal cortical adenoma were not prominent features. The nuclei had prominent nucleoli.

\section{Discussion KIN}

Twenty-seven cases of adrenocortical oncocytic neoplasms have been reported to date, which comprised 22 oncocytomas, 2 oncocytic neoplasms of uncertain malignant potential, and 3 oncocytic carcinomas (1-14). All arose in the adrenal gland with

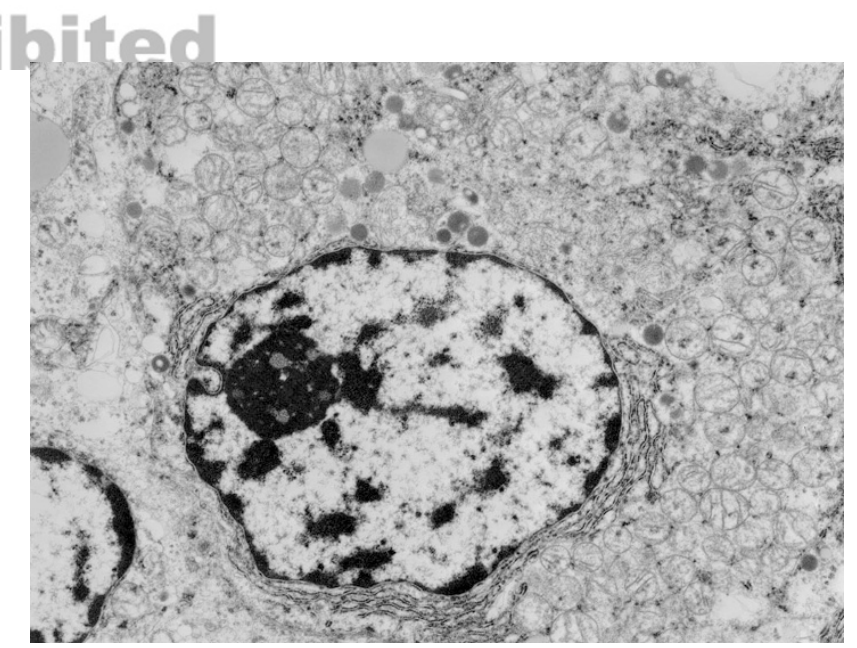

FIGURE 8. Prominent nucleoli, perinuclear rough endoplasmic reticulum, numerous cytoplasmic mitochondria, and lipid droplets are noted ultrastructurally. 


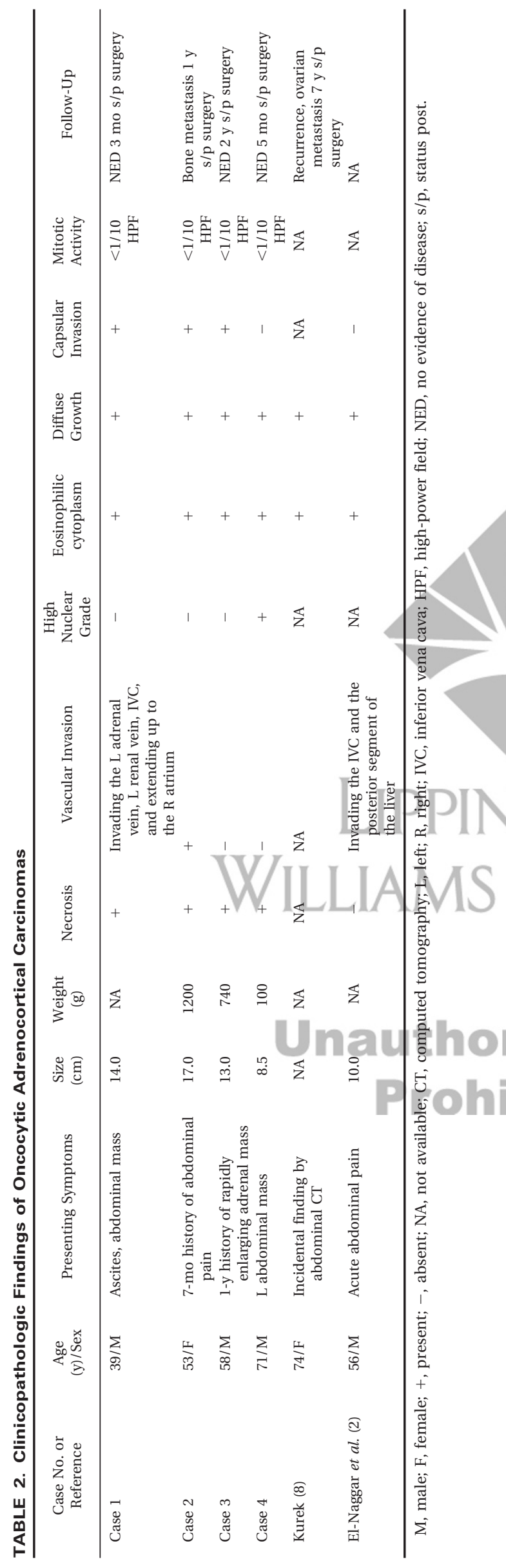

the exception of one oncocytoma that originated in heterotopic right supra-adrenal retroperitoneal tissue (11). All have been reported to be nonfunctional except one oncocytic adenoma that produced virilizing symptoms (3).

The main differential diagnosis of our cases is adrenal cortical oncocytoma. The majority of adrenal cortical oncocytomas are well-circumscribed tumors with size ranging from 3 to $15 \mathrm{~cm}$. Although they show cytologic atypia, necrosis, capsular extension and vascular invasion are not identified. The differential diagnosis also includes conventional adrenal cortical carcinoma, pheochromocytoma, eosinophilic variant of chromophobe renal cell carcinoma, and metastatic hepatocellular carcinoma. Many adrenocortical tumors have foci of oncocytic neoplastic cells (15); however, our tumors were composed exclusively of oncocytes. Neoplastic cells with foamy cytoplasm were only noted focally in two cases (less than 5\%). Inhibin has recently been shown to stain the majority of adrenocortical tumors (16); however, it was expressed in only one of our four cases of oncocytic adrenocortical carcinomas. Pheochromocytomas are functional tumors that produce episodic hypertension. They have a zellballen pattern and exhibit chromogranin immunoreactivity and the sustentacular cells express S-100 protein. Moreover, electron microscopy would reveal abundant dense-core membrane-bound granules rather than mitochondria. The oncocytic variant of renal cell carcinoma may involve the adrenal gland. However, renal cell carcinomas are usually immunoreactive for epithelial membrane antigen and have cytoplasmic vesicles ultrastructurally and are inhibin negative (17). Our tumors focally have a trabecular pattern with cords of neoplastic cells separated by sinusoids, lined by flattened endothelial cells. Hepar-1 immunostain would easily exclude the possibility of metastatic hepatocellular carcinoma.

Various systems have been proposed to distinguish benign from malignant adrenocortical tumors (18). According to Weiss $(19,20)$, adrenocortical carcinoma would have four or more of the following findings: high nuclear grade, eosinophilic cytoplasm (more than $75 \%$ ), diffuse architecture (more than 33\%), and presence of necrosis, mitotic figures (more than $5 / 50 \mathrm{HPFs}$ ), atypical mitotic figures, capsular invasion, venous invasion, and sinusoidal invasion. Of these, a mitotic rate greater than 5 per $50 \mathrm{HPF}$, atypical mitotic figures, and venous invasion were found only in malignant tumors. Other studies of conventional adrenal cortical carcinoma found that mitotic rate and nuclear pleomorphism were the features most supportive of malignancy $(15,21)$. However, cytologic atypia or mitotic rate cannot reliably predict the biologic behavior of oncocytic adrenocortical neoplasms. In reviewing the clinicopathologic features of our four cases and the two previously documented cases of oncocytic adrenocortical carcinomas (Table 2), we 
found that all our tumors showed a diffuse proliferation of oncocytic cells with prominent nucleoli but with less than 1 mitotic figure per $10 \mathrm{HPFs}$. Large tumor size, vascular invasion, capsular extension, metastasis and surgical unresectability are features of malignancy for oncocytic adrenocortical carcinomas.

Markers such as P53 and Ki-67 have been proposed to be potential predictive markers of biologic behavior of adrenocortical neoplasms (22). However, findings in isolated case reports and small series have not shown Ki-67, a proliferation marker, to be useful in oncocytic adrenocortical carcinomas $(7,9)$. One of our tumors expressed p53, while p53 expression was absent in the benign and borderline oncocytic adrenocortical tumors in a series by Lin et al. (9). Moreover, loss of heterozygosity at $17 \mathrm{p}$, the chromosomal arm that housed the p53 gene locus, was documented by microsatellite analysis of a recurrent oncocytic adrenocortical carcinoma with ovarian metastasis (8). These findings suggest that p53 tumor suppressor gene may play a role in malignant transformation of some oncocytic adrenocortical neoplasms. Unfortunately, the role of either Ki-67 or p53 as biomarkers likely remains uncertain due to the availability of so few of these tumors.

The ultrastructural findings of our cases are similar to those previously reported adrenal oncocytomas and oncocytic adrenocortical carcinomas. The cytoplasm is filled with numerous mitochondria, remarkable for their abnormalities in size, shape, and cristae structure $(23,24)$. Minimal knowledge is available of the mechanisms that lead to oncocytosis in general and in adrenocortical cells in particular. Experimental studies in rats have demonstrated that $\mathrm{N}$-nitrosomorpholine induced renal oncocytosis and followed by the formation of renal oncocytoma (25). These findings suggest that mitochondrial proliferation is a compensatory mechanism. Another hypothesis is that oncocytomas are tumors of mitochondria since mitochondria have their own DNA that codes their own characteristic proteins (26). Differentiation towards cells of highenergy output, a response to defect in the energy production machinery of the cell, is another possible explanation for the oncocytic appearance of these tumors (27).

We present four cases of non-functioning oncocytic adrenocortical carcinomas whose malignant biologic behavior is evidenced by direct tumor extension, venous invasion, extracapsular involvement and bone metastasis. The treatment of these tumors is complete surgical excision.

\section{REFERENCES}

1. Begin LR. Adrenocortical oncocytoma: case report with immunocytochemical and ultrastructural study. Virchows Arch 1992;421:533-7.
2. El-Naggar AK, Evans DB, Mackay B. Oncocytic adrenal cortical carcinoma. Ultrastruct Pathol 1991;15:549-56.

3. Erlandson RA, Reuter VE. Oncocytic adrenal cortical adenoma. Ultrastruct Pathol 1991;15:539-47.

4. Gandras EJ, Schwartz LH, Panicek DM, Levi G. Adrenocortical oncocytoma: CT and MRI findings. J Comput Assist Tomogr 1996;20:407-9.

5. Kakimoto S, Yushita Y, Sanefuji T, et al. Non-hormonal adrenocortical adenoma with oncocytoma-like appearances. Acta Urol Jpn 1986;32:757-63.

6. Kitching PA, Patel V, Harach R. Adrenocortical oncocytoma. J Clin Pathol 1999;52:151-3.

7. Krishnamurthy S, Ordonez NG, Shelton TO, Ayala AG, Sneige N. Fine-needle aspiration cytology of a case of oncocytic adrenocortical carcinoma. Diagn Cytopathol 2000;22:299-303.

8. Kurek R, Knobloch RV, Feek U, Heidenreich A, Hofmann R. Local recurrence of an oncocytic adrenocortical carcinoma with ovary metastasis. J Urol 2001;166:985.

9. Lin BTY, Bonsib SM, Mierau GW, Weiss LM, Medeiros LJ. Oncocytic adrenocortical neoplasms: a report of seven cases and review of the literature. Am J Surg Pathol 1998;22:603-14.

10. Muir TE, Ferreiro JA, Carney JA. Oncocytoma of the adrenal gland [abstract]. Mod Pathol 1996;9:50A.

11. Nguyen G-K, Vriend R, Ronaghan D, Lakey WH. Heterotopic adrenocortical oncocytoma. A case report with light and electron microscopic studies. Cancer 1992;70:2681-4.

12. Sasano H, Suzuki T, Sano T, et al. Adrenocortical oncocytoma. A true nonfunctioning adrenocortical tumor. Am J Surg Pathol 1991;15:949-56.

13. Segal S, Cytron S, Shenhav S, Gemer O. Adrenocortical oncocytoma in pregnancy. Obstet Gynecol 2001;98:916-8.

14. Walters PR, Haselhuhn GD, Gunning WT, et al. Adrenocortical oncocytoma: two case reports and review of the literature. Urology 1997;49:624-8.

15. Evans HL, Vassilopoulou-Sellin R. Adrenal cortical neoplasms: a study of 56 cases. Am J Clin Pathol 1996;105:76-86.

16. Chivite A, Matias-Giuiu X, Pons C, Algaba F, Prat T. Inhibin A expression in adrenal neoplasms. Appl Immunohistochem 1998;6:42-9.

17. Thoenes W, Storkel S, Rumpelt HJ, Moll R, Baum HP, Werner S. Chromophobe renal cell carcinoma and its variants: a report of 32 cases. J Pathol 1988;155:277-87.

18. Medeiros LJ, Weiss LM. New developments in the pathologic diagnosis of adrenal cortical neoplasms: a review. Am J Clin Pathol 1992;97:73-83.

19. Weiss LM. Comparative histologic study of 43 metastasizing and nonmetatasizing adrenocortical tumors. Am J Surg Pathol 1984;8:163-9.

20. Weiss LM, Medeiros LJ, Vickery AL. Pathologic features of prognostic significance in adrenocortical carcinoma. Am J Surg Pathol 1989;13:202-6.

21. Venkatesh S, Hickey RC, Sellin RV, Fernandez JF, Samaan NA. Adrenal cortical carcinoma. Cancer 1989;64:765-9.

22. Vargas MP, Vargas HI, Kleiner DE, Merino MJ. Adrenocortical neoplasms: role of prognostic markers MIB-1, p53, and RB. Am J Surg Pathol 1997;21:556-62.

23. Chang A, Harawi SJ. Oncocytes, oncocytosis, and oncocytic tumors. Pathol Annu 1992;27:263-304.

24. Mackay B, El-Naggar A, Ordonez NG. Ultrastructural of adrenal cortical carcinoma. Ultrastruct Pathol 1994;18:181-90.

25. Krech R, Zerban H, Bannasch P. Mitochondrial anomalies in renal oncocytes induced in rats by $N$-nitrosomorpholine. Eur J Cell Biol 1981;25:331-9.

26. Sun CN, White HV, Thompson BW. Oncocytoma (mitochondrioma) of the parotid gland. Arch Pathol 1975;99:208-14.

27. Hartwick RW, Batsakis JG. Non-Warthin's tumor oncocytic lesions. Ann Otol Rhinol Laryngol 1990;99:674-7. 